\title{
Social cognition profile in amnestic MCI
}

\author{
Amer M S, ${ }^{1,2}$ Adly N N, ${ }^{1,2}$ Rasheedy D, ${ }^{1,2}$ Mahdy $\mathbf{R}^{1,2}$ \\ 1 Geriatrics \& Gerontology department, Faculty of Medicine, Ain Shams University, Cairo, Egypt. \\ 2Ain Shams Ageing Research Center.
}

\begin{abstract}
Background: For years, disturbance of social cognition was considered as an early feature of schizophrenia and autism. Recently, it has been studied in many neurodegenerative diseases, and included as one of the six key domains of cognitive function defined by DSM- V. Mild cognitive impairment (MCI) is a transitional state between normal cognitive aging and dementia, mainly of $A D$ type. Few reports have addressed theory of mind (ToM) capacity in patients with $\mathrm{MCl}$
\end{abstract}

Aim: To detect ToM impairment among amnestic $\mathrm{MCl}$ patients and to characterize the neuropsychological and functional profiles of $\mathrm{MCl}$ cases according to their ToM capacity.

Methods: 40 elderly diabetic patients with amnestic $\mathrm{MCl}$ were recruited. Each patient underwent cognitive, and functional assessment. The second order false belief (John and Merry story) test was used to assess social cognition.

Results: There was no significant difference between cases with and without impaired social cognition regarding age, ADL,or IADL, while MMSE scores were significantly lower among cases with impaired second order belief. Stick design tests, and digit span tests were significantly affected in the cases with impaired social cognition.

Conclusions: Social cognition was impaired in about $17.5 \%$ of patients with $\mathrm{MCl}$, which was not reflected upon functional status. $\mathrm{MCl}$ patients with impaired social cognition, performed worse in the stick design test and the digit span forward test.

Keywords: Theory of mind, social cognition, second order false belief

\section{Background:}

Social Cognition was defined by Fiske, $1993^{1}$ as the means by which we make sense of ourselves in relation to others and the environment in which we live. Decades later, Forbes \& Grafman, $2010^{2}$ demonstrated that social cognition includes any cognitive process that is utilized to understand or interpret the self in relation to others.

For years, disturbance of social cognition was considered as an early feature of schizophrenia and autism. Recently, it has been studied in many neurodegenerative diseases, and included as one of the six key domains of cognitive function defined by DSM$\mathrm{V}^{3}$.

According to DSM-V ${ }^{3}$, social cognition has 3 subdomains which include recognition of emotions, theory of mind, and insight. Theory of Mind (ToM) is the main subdomain of social cognition. It is the ability we attribute mental states (beliefs, intentions, or knowledge) to ourselves and others ${ }^{4}$.

ToM capacity can be assessed by different tests including the first- and second-order false belief tasks, the Faux Pas Recognition (FPR) test, the Reading the Mind in the Eyes (RME) test and Ekman's Facial Emotion Recognition Test. ${ }^{5}$

ToM impairment in patients with dementia was largely observed in early cases of frontotemporal lobe degeneration. ${ }^{6,7}$ In Alzheimer's disease (AD), the high levels of ToM i.e. second-order belief tasks were impaired, even in the early course of the disease. ${ }^{6,8,9}$ 
However, other studies reported the affection of more basic levels of ToM in early AD i.e. gaze detection or first-order false belief tasks. ${ }^{10,11}$

Mild cognitive impairment (MCI) is a transitional state between normal cognitive aging and dementia, mainly of AD type. Few reports have assessed addressed ToM capacity in patients with MCI. ${ }^{4,12,13}$

The aim of the current study was to detect ToM impairment among amnestic MCI patients and to characterize the neuropsychological and functional profiles of MCI cases according to their ToM capacity.

\section{Methods}

\section{Study population}

A cross sectional study was conducted on 40 elderly diabetic patients with amnestic MCI attending the outpatient clinics in Ain Shams University Hospital, Cairo, Egypt.

The subjects who refused or could not complete the interview were excluded from the study. Any subject with a history of head trauma, CNS pathology, depression, dementia, or delirium, or using anticholinergic drugs were excluded from the study.

\section{Ethical consideration:}

The study methodology was reviewed and approved by the Research Review Board of the Geriatrics and Gerontology Department, Faculty of Medicine, Ain Shams University. Informed consent was taken from every subject participating in this study.

All participants underwent comprehensive geriatric assessment that included detailed personal and medical histories, physical examination, cognitive and functional, and mood assessment tests.

\section{Cognitive assessment:}

Using the Arabic version of mini-mental state examination (MMSE) ${ }^{14}$ and the second order false belief (John and Merry story) test to assess ToM as a subdomain of social cognition.

\section{Functional assessment:}

Functional assessment was performed using Activities of daily living (ADL), ${ }^{15}$ and Instrumental activities of daily living (IADL). ${ }^{16}$

\section{Statistical Analysis}

The collected data were coded, tabulated, revised and statistical analyzed using SPSS program (version 16). Quantitative variables were presented in the form of means and standard deviation.

Qualitative variables were presented in form of frequency tables (number and percent). Comparison was made by the Student t-test. The qualitative variables were compared by using the chi-square test. $\mathrm{P}$ value is considered significant if equal to or less than 0.05 frequency tables (number and percent).

\section{Results}

Forty elderly were enrolled in this study, 27(67.5\%) of them were males, $28(70.0 \%)$ were illiterate, $28(70.00 \%)$ were functionally disabled in ADL (score $<6)$, and $27(67.5 \%)$ were functionally disabled in IADL (score $<8$ ).

The mean age of the participants was $64.97 \pm 3.39$ years.

Seven $(17.5 \%)$ of the participants had impaired social cognition as assessed by second order belief (John and Merry story) test.

Table 1: comparison between the cases with and without impaired social cognition

\begin{tabular}{|c|c|c|c|c|}
\hline & & $\begin{array}{l}\text { impairment } \\
\text { Merry story }\end{array}$ & rding to John & $\begin{array}{l}\text { P- } \\
\text { value }\end{array}$ \\
\hline & & $\begin{array}{l}\text { Intact } \\
33(82.5 \%)\end{array}$ & $\begin{array}{l}\text { impaired } \\
7(17.5 \%)\end{array}$ & \\
\hline Age mean & & $64.93(3.53)$ & $65.14(2.85)$ & 0.888 \\
\hline Body mass & $x$ mean & $28.58(5.7)$ & $28.67(7.03)$ & 0.972 \\
\hline & & $23.87(1.83)$ & $22.14(0.889)$ & $0.02 *$ \\
\hline MMSE me & D) & & & \\
\hline $\begin{array}{l}\text { ADL total } \\
\text { (SD) }\end{array}$ & mean & $4.69(1.26)$ & $4.28(0.95)$ & 0.42 \\
\hline $\begin{array}{l}\text { IADL tota } \\
\text { (SD) }\end{array}$ & e mean & $6.24(1.95)$ & $5.85(1.36)$ & 0.62 \\
\hline Education & Illiterate & $21(63.3 \%)$ & $7(100 \%)$ & $0.05 *$ \\
\hline & $\begin{array}{l}\text { Can read } \\
\text { and write }\end{array}$ & $12(36.7 \%)$ & $0(0.0 \%)$ & \\
\hline
\end{tabular}

.There was no significant difference between cases with and without impaired social cognition regarding age, ADL, or IADL, while MMSE scores were significantly lower among cases with impaired second order belief. [Table 1]

There were statistical significant differences between the cases with and without impaired social cognition as regards items of dressing, food preparation, reading and writing in ADL, IADL, and MMSE. [Table 2]

Executive function and complex attention were significantly affected in the cases with impaired social cognition. [Table 3] 
Table 2: Descriptive ADL, IADL, and MMSE profiles in cases according to TOM

\begin{tabular}{|c|c|c|c|c|c|c|c|}
\hline Items affected & $\begin{array}{l}\text { Impaired } \\
\text { ToM }\end{array}$ & Intact ToM & $\begin{array}{l}\mathbf{P} \\
\text { value }\end{array}$ & Items affected & $\begin{array}{l}\text { Impaired } \\
\text { ToM }\end{array}$ & Intact ToM & $\begin{array}{l}P \\
\text { value }\end{array}$ \\
\hline \multicolumn{8}{|l|}{ ADL } \\
\hline Feeding & 0 & $\mathbf{0}$ & & Medication management & $5(71.42 \%)$ & $18(54.5 \%)$ & 0.41 \\
\hline Continence & $6(85.71 \%)$ & $22(66.7 \%)$ & 0.65 & Food preparation & $6(85.71 \%)$ & $14(42.42 \%)$ & $0.03 *$ \\
\hline Toileting & $0(\mathbf{0} \%)$ & $3(9.09 \%)$ & 0.40 & $\underline{\text { MMSE }}$ & & & \\
\hline Dressing & $5(71.42 \%)$ & $11(33.33 \%)$ & $0.05 *$ & Time orientation & $5(71.42 \%)$ & $18(54.5 \%)$ & 0.41 \\
\hline Bathing & $\mathbf{0}(\mathbf{0} \%)$ & $4(12.12 \%)$ & 0.33 & Place orientation & $5(71.42 \%)$ & $18(54.5 \%)$ & 0.41 \\
\hline Transfer & $1(14.28 \%)$ & $6(18.18 \%)$ & 0.85 & Registration & $2(28.57 \%)$ & $7(21.21 \%)$ & 0.67 \\
\hline$\underline{\mathbf{I A D L}}$ & & & & Calculation & $7(100 \%)$ & $32(96.7 \%)$ & 0.64 \\
\hline Telephone use & $\mathbf{0}(\mathbf{0 \%})$ & $1(3.03 \%)$ & 0.64 & Recall & $7(100 \%)$ & $29(87.8 \%)$ & 0.33 \\
\hline Handling finance & $1(14.28 \%)$ & $4(12.12 \%)$ & 0.87 & Language & $2(28.57 \%)$ & $3(9.09 \%)$ & 0.15 \\
\hline Laundry & $\mathbf{0}(0 \%)$ & $4(12.12 \%)$ & 0.33 & 3 order command & $\mathbf{0}$ & $1(3.03 \%)$ & 0.64 \\
\hline Shopping & $1(14.28 \%)$ & $4(12.12 \%)$ & 0.87 & Reading & $7(100 \%)$ & $21(63.4 \%)$ & $0.05 *$ \\
\hline Transportation & $0(0 \%)$ & $4(12.12 \%)$ & 0.33 & Writing & $7(100 \%)$ & $21(63.4 \%)$ & $0.05 *$ \\
\hline House keeping & $2(28.57 \%)$ & $9(27.27 \%)$ & 0.94 & Copy design & $6(85.71 \%)$ & $22(66.7 \%)$ & 0.31 \\
\hline
\end{tabular}

*Statistical significance

Table 3: the affected cognitive domains among cases according to ToM performance

\begin{tabular}{|c|c|c|c|c|}
\hline \multicolumn{2}{|c|}{$\begin{array}{l}\text { Impaired cognitive } \\
\text { domain }\end{array}$} & \multicolumn{2}{|c|}{$\begin{array}{l}\text { impairment according to } \\
\text { John Merry story }\end{array}$} & \multirow[t]{2}{*}{$\begin{array}{l}P \text { - } \\
\text { value }\end{array}$} \\
\hline & & $\begin{array}{l}\text { Intact } \\
33(82.5 \%)\end{array}$ & $\begin{array}{l}\text { impaired } \\
7(17.5 \%)\end{array}$ & \\
\hline \multirow{2}{*}{\multicolumn{2}{|c|}{$\begin{array}{l}\text { stick design test } \\
\text { Animal fluency teat }\end{array}$}} & $6(18.18 \%)$ & $4(57.14 \%)$ & $0.031 *$ \\
\hline & & $11(33.3 \%)$ & $5(71.42 \%)$ & 0.06 \\
\hline $\begin{array}{l}\text { digit } \\
\text { span }\end{array}$ & Forward & $\begin{array}{l}13 \\
(39.39 \%)\end{array}$ & $6(85.71 \%)$ & $0.026 *$ \\
\hline tests & backward & $26(78.78 \%$ & $7(100 \%)$ & 0.18 \\
\hline \multicolumn{2}{|c|}{ go-no-go test } & $8(24.24 \%)$ & $3(42.85 \%)$ & 0.31 \\
\hline $\begin{array}{l}\text { logical } \\
\text { memory }\end{array}$ & $\begin{array}{l}\text { Immediate } \\
\text { recall }\end{array}$ & $32(96.7 \%)$ & $7(100 \%)$ & 0.64 \\
\hline test & $\begin{array}{l}\text { Delayed } \\
\text { recall }\end{array}$ & $6(85.71 \%)$ & $6(85.71 \%)$ & 0.87 \\
\hline
\end{tabular}

${ }^{*}$ statistical significance

\section{Discussion}

In the recent years, interest increased in social cognition in neurodegenerative diseases. Insufficient social cognitive function in frontotemporal dementia possibly account for the early social inappropriateness among these patients. ${ }^{17}$

In $\mathrm{AD}$ and its prodromal stage (MCI), the deficits in TOM were suggested to be secondary to their primary memory impairment. ${ }^{17}$

The impaired cognitive component of ToM is well documented in $\mathrm{AD}$; however, controversial data exist regarding the affective component of ToM which is mainly a function of medial portions of the prefrontal cortex. ${ }^{13}$

To date, few studies have reported occurrence of TOM in MCI. ${ }^{4,12,13}$ The main goal of the current study was to detect ToM impairment among amnestic MCI patients and to characterize the neuropsychological and functional profiles of cases according to the ToM capacity.

In this study, $7(17.5 \%)$ of the participants had impaired ToM assessed by second order false belief test. This result proves that impaired social cognition may occur prior to dementia development, which agrees with previous studies. ${ }^{12,13}$

Although MMSE is not a sensitive test for detecting MCI in elderly ${ }^{18}$, the MMSE score in cases with and without impaired ToM was $23.82 \pm 1.91$, this agrees with another study in Nigeria ${ }^{19}$, due to low educational level of the participants in both studies. Those with and without impaired ToM differ significantly in the degree of cognitive decline measured by MMSE scores.

This finding did not agree with previous studies. ${ }^{4,13}$ They reported that the risk for ToM impairment was not related to the severity of general cognitive decline. This difference can be attributed to the significant difference in the educational level between the two groups.. 
The current study reported that $28(70.00 \%)$ of the patients were functionally disabled in ADL (score <6), and $27(67.5 \%)$ were functionally disabled in IADL (score <8). Although, the defect in performing different items of ADL is not included as a criterion for diagnosis of $\mathrm{MCI}^{(3)}$, this study as well as, the study performed by Roberts et al. $2008^{20}$ found that self-care items in ADL were affected in patient with MCI.

The current study found that dressing was the most affected item in ADL among cases with and without impaired social cognition. This could be due to the presence of other precipitating factors as early loss in dressing is against the loss of functional hierarchy

${ }^{21}$ Yet the performance of different ADL items was not affected by impaired ToM.

Impairment in IADL typically precedes the impairment in basic activities of daily living in the settings of cognitive decline. ${ }^{22}$ There was no significant difference between cases with and without impaired social cognition regarding IADL except for dependency in food preparation. This may indicate executive dysfunction that was also observed by significant difference in performing stick design test, attributed to the reflection of stick design test to the executive function. ${ }^{23}$

Contradictory observations exist regarding the relationship between ToM and executive function. Aboulafia-Brakha et al. ${ }^{24}$ in their meta- analysis showed a congruent association between ToM and executive function in $64 \%$ of studies and incongruent associations in $29 \%$ of studies.

Digit span tests are indicators of complex attention affection; ${ }^{25}$ there was significant difference in performing digit span tests between cases with and without impaired social cognition. The observation regarding the association between attention and socioemotional difficulties possibly caused by deficits in TOM was previously noted in children with attention deficit/hyperactivity disorder. ${ }^{26}$ Similar associations were not examined among elderly with neurodegenerative diseases; this can be a target for future research.

\section{Conclusion:}

Impaired social cognition in neurodegenerative diseases is now well documented in MCI. Functional profiles of amnestic MCI cases with impaired ToM did not differ from those with intact ToM except for food preparation and dressing. MCI patients with impaired social cognition, performed worse in the stick design test and the digit span forward test suggesting that executive control may interfere with automatic stereotyping.
Our study had several limitations; firstly, due to the small sample size, its statistical power might be insufficient. Secondly, we did not examine the social impact of ToM impairments. Thirdly, we did not examine different tests to assess affective and cognitive ToM. Larger studies are needed to determine the ToM capacity in MCI cases compared to healthy elderly. ToM should be assessed in all cases with amnestic MCI.

\section{References}

1. Fiske ST. Social Cognition and Social Perception. Annual Review of Psychology.1993;44: 155-194

2. Forbes CE, Grafman J. The role of the human prefrontal cortex in social cognition and moral judgment. Annu Rev Neurosci. 2010;33:299-324

3. American Psychiatric Association Diagnostic and Statistical Manual of Mental Disorders 5th ed (American Psychiatric Association, 2013

4. Moreau, N., Rauzy, S., Bonnefoi, B., Renié, L., Martinez-Almoyna, L. Viallet, F., \& Champagne-Lavau, M. Different patterns of theory of mind impairment in mild cognitive impairment. Journal of Alzheimer's Disease. 2015, 45, 581-597

5. Kemp J, Despres O, Sellal F, Dufour A. Theory of mind in normal ageing and neurodegenerative pathologies. Ageing Res Rev. 2012;11:199-219

6. Gregory C, Lough S, Stone V, Erzinclioglu S, Martin L, BaronCohen $S$, et al. Theory of mind in patients with frontal variant frontotemporal dementia and Alzheimer's disease: theoretical and practical implications. Brain. 2002;125:752-64.

7. Henry JD, Phillips LH, von Hippel C. A meta-analytic review of theory of mind difficulties in behavioural-variant frontotemporal dementia. Neuropsychologia. 2014;56:53-62.

8. Fernandez-Duque D, Baird JA, Black SE. False-belief understanding in frontotemporal dementia and Alzheimer's disease. J Clin Exp Neuropsychol.2009: 31, 489-497.

9. Zaitchik D, Koff E, Brownell H, Winner E, Albert M. Inference of beliefs and emotions in patients with Alzheimer's disease. Neuropsychology.2006: 20, 11-20.

10. Castelli I, Pini A, Alberoni M, Liverta-Sempio O, Baglio F, Massaro D. Marchetti A, Nemni R. Mapping levels of theory of mind in Alzheimer's disease: A preliminary study. Aging Ment Health.2011: 15, 157-168.

11. Cuerva AG, Sabe L, Kuzis G, Tiberti C, Dorrego F, Starkstein SE Theory of mind and pragmatic abilities in dementia. Neuropsychiatry Neuropsychol Behav Neurol. 2001: 14, 153-158.

12. Baglio F, Castelli I, Alberoni M, Blasi V, Griffanti L, Falini A, Nemni $R$, Marchetti A. Theory of mind in amnestic mild cognitive impairment: An FMRI study. J Alzheimers Dis. 2012: 29, 25-37.

13. Poletti M, Bonuccelli U. Alteration of affective Theory of Mind in amnestic mild cognitive impairment. J Neuropsychol. 2013: 7, 121131.

14. El Okl MA, El banouby MH, Mortagy AK, et al. Prevalence of $A D$ and other types of dementia in Egypt. Tenth Congress of the International Psychogeriatrics Association. International Psychogeriatrics 2001;13:114-S.

15. Katz S, Downs TD, Cash HR, Grotz RC. Progress in development of the index of ADL. Gerontologist.1963;10:20-30.

16. Lawton MB and Brody EM. Assessment of older people: selfmaintaining and instrumental activities of daily living. Gerontologist. 1969: 9:179-86.

17. Modinos G, Obiols JE, Pousa E, and Vicens J. Theory of Mind in Different Dementia Profiles. The Journal of Neuropsychiatry and Clinical Neurosciences.2009: 21(1); 100-101.

18. Benedict RH, Brandt J. Limitation of the Mini-Mental State Examination for the detection of amnesia. Journal of Geriatric Psychiatry \& Neurology. 1992;5(4):233-237.

19. Onwuekwe 1O. Assessment of Mild Cognitive Impairment with Mini Mental State Examination Among Adults in Southeast Nigeria. 2012; 2(2): 99-102.

20. Roberts RO, Geda YE, Knopman DS, et al. Association of duration and severity of diabetes mellitus with mild cognitive impairment. Archives of Neurology.2008; 65(8):1066-1073.

21. Eager $\mathrm{K}$ and Owen $\mathrm{A}$ functional screeing and assessment, why and 
Amer et al. EJGG.2017; 4(2):10-14

how. Centre for health service development. university of

22. Njegovan V, Hing MM, Mitchell SL, Molnar FJ. The hierarchy of functional loss associated with cognitive decline in older persons. J. Gerontol. A: Biol. Sci. Med. Sci.2001; 56: 638-643.

23. de Paula JJ, Bertola L, A' vila RT, Moreira L, Coutinho G, et al. (2013) Clinical Applicability and Cutoff Values for an Unstructured Neuropsychological Assessment Protocol for Older Adults with Low Formal Education. PLoS ONE 8(9): e73167.

24. Aboulafia-Brakha T, Christe B, Martory MD, Annoni JM. Theory of mind tasks and executive functions: a systematic review of group studies in neurology. J Neuropsychol. 2011:5:39-55.
Wollongong.2002

25. Rosenthal, EN, Riccio, CA, Gsanger, KM, \& Jarratt, KP. Digit span components as predictors of attention problems and executive functioning in children. Archives of Clinical Neuropsychology 2006; 2, 131-139.

26. Mary A, Slama H, Mousty P, Massat I, Capiau T, Drabs V, Peigneux $P$. Executive and attentional contributions to Theory of Mind deficit in attention deficit/hyperactivity disorder (ADHD). Child Neuropsychol. 2016;22(3):345-65. 